\title{
Avaliação Imunoistoquímica da Proteína Ciclooxigenase-2 nas Neoplasias Colorretais e sua Relação com Fatores Patológicos Prognósticos
}

\author{
Immunohistochemical Evaluation of Cyclooxygenase-2 in Colorectal Neoplasias \\ and Relationship with Pathological Factors in Prognosis
}

\author{
BRAMBILLA, E';MOREIRA, LUIS FERNANDO²; SERAFINI, EDUARDO PRETTO .
}

${ }^{1}$ Professor da UEM Aparelho Digestivo da Universidade de Caxias do Sul; Membro Titular da Sociedade Brasileira de Coloproctologia; ${ }^{2}$ Professor do Curso de Pós-Graduação em Cirurgia da Universidade Federal do Rio Grande do Sul;

${ }^{3}$ Professor do departamento de Patologia da Universidade de Caxias do Sul.

BRAMBILLA E; MOREIRA LF; SERAFINI EP. Avaliação Imunoistoquímica da Proteína Ciclooxigenase-2 nas Neoplasias Colorretais e sua Relação com Fatores Patológicos Prognósticos. Rev bras Coloproct, 2007;27(3): 256-263.

Resumo: Objetivos: Avaliar a prevalência da proteína ciclooxigenase-2 (COX-2) nas neoplasias colorretais e sua relação com os parâmetros patológicos prognósticos para o câncer colorretal. Métodos: 65 lesões neoplásicas colorretais foram avaliadas através de imunoistoquímica para a presença de COX-2, também foram analisados fatores patológicos prognósticos e estadiamento das lesões. Resultados: A COX-2 expressou-se positivamente em $27 \%$ dos adenomas tubulares, $40 \%$ dos adenomas vilosos e $70 \%$ nos carcinomas. Diferença estatisticamente significante foi obtida na expressão da COX-2 entre adenomas e carcinomas, porém não houve significância nas demais variáveis estudadas. Conclusão: A expressão da COX-2 parece variar progressivamente com a progressão da lesão neoplásica, mas não influencia os parâmetros patológicos de mau prognóstico.

Descritores: Ciclooxigenase-2, câncer colorretal, imunoistoquimica, carcinogenese.

\section{INTRODUÇÃO}

A neoplasia de cólon e reto constitui a terceira causa de mortalidade por câncer no mundo e nos Estados Unidos é responsável pelo aparecimento de 130.000 novos casos por ano e por cerca de 56.000 mortes ${ }^{1}$. Devido a esta frequiência elevada, métodos que possam trazer novas perspectivas nos campos do diagnóstico precoce, estadiamento, tratamento e profilaxia desta patologia tornam-se de grande interresse.

Estudos epidemiológicos têm demonstrado uma incidência menor de adenomas e carcinomas em indivíduos que usam cronicamente antiinflamatórios não esteróides (AINES) ${ }^{2,3,4}$. Também trabalhos com indivíduos portadores de polipose adenomatosa familiar, uma doença pré-maligna, mostram uma regressão no número e tamanho dos pólipos quando submetidos ao uso crônico de AINES 5 .

Os AINES possuem como mecanismo de ação a inibição da enzima ciclooxigenase (COX). A COX possui duas isoformas que são derivadas de genes diferentes, mas possuem uma homologia de $60 \%$ em sua estrutura. A COX-1 é expressa constitutivamente nos tecidos, enquanto a COX-2 é usualmente ausente ou expressa em quantidades muito pequenas ${ }^{6,7}$. A COX-2 é induzida por estímulos pró-inflamatórios como citocinas e fatores de crescimento, bem como se apresenta elevada em uma grande variedade de neoplasias como nas lesões colorretais ${ }^{8}$. Em vários experimentos que avaliam a deleção do gene da COX-2 ou a inibição seletiva da proteína COX-2, observou-se redução sig- 
Avaliação Imunoistoquímica da Proteína Ciclooxigenase-2 nas Neoplasias

Colorretais e sua Relação com Fatores Patológicos Prognósticos

Brambilla e Cols. nificativa no crescimento dos pólipos e no desenvolvimento de tumores ${ }^{9,10,11}$.

Ainda persistem dúvidas sobre o verdadeiro papel da COX-2 no aparecimento e progressão dos tumores colorretais. Neste estudo avaliou-se a expressão da COX-2 nos diferentes estágios da neoplasia colorretal, relacionando-a também com fatores prognósticos conhecidos como tipo de crescimento tumoral, presença de padrão microacinar, caráter mucinoso do tumor e presença de estroma fibrótico.

\section{METODOLOGIA}

Este trabalho consiste em um estudo de prevalência onde os fatores em estudo são as características patológicas do tumor primário e o desfecho é a expressão imunoistoquímica da proteína ciclooxigenase- 2 .

Foram avaliados 35 pacientes portadores de adenocarcinoma de cólon ou reto, e 30 pacientes portadores de pólipos adenomatosos nos mesmos segmentos ressecados cirúrgica ou endoscopicamente. As lâminas para a análise da proteína COX-2 foram preparadas a partir de blocos de parafina da peças cirúrgicas ou ressecções endoscópicas.

Foram incluídos os pacientes com adenocarcinoma ou adenoma de cólon e reto e foram excluídos da amostra os que preenchiam os critérios a seguir: a) neoplasias que não fossem diagnosticadas como adenomas ou adenocarcinoma; b) outras neoplasias concomitantes ou tumores prévios; c) neoplasia maligna sincrônica ou metacrônica do intestino grosso; d) portadores de doença inflamatória intestinal ou; e) polipose de qualquer tipo; f) história familiar de neoplasia de cólon ou reto; g) terapia neoadjuvante; ou ainda h) uso crônico de AINES.

As variáveis estudadas foram: idade, gênero, localização, grau histológico, produção de muco, caráter infiltrativo da lesão, aspecto do estroma, padrão microacinar, presença de metástases linfáticas ou a distância, estágio e expressão imunoistoquimica da proteína COX-2; todas coletadas em revisão de prontuários médicos e avaliação das lâminas existentes e escolha dos blocos mais representativos de cada lesão e avaliação histopatológica, respectivamente.

Os cortes dos blocos de parafina estocados das peças cirúrgicas foram submetidos à avaliação imunoistoquímica utilizando-se o anticorpo monoclonal anti-COX-2 (IgG, Dako Lab., New York, USA). Para determinação da positividade destes anticorpos nos tecidos, foi utilizado o método imunoistoquímico $\mathrm{ABC}$ (avidin-biotin-peroxidase complex; kit LSAB DAKO), conforme se segue.

Para aderência dos cortes dos blocos de parafina às lâminas foi utilizado o organo selano. Para desparafinização, as lâminas foram colocadas em estufa a $37^{\circ} \mathrm{C}$ por $24 \mathrm{~h}$ e a $56^{\circ} \mathrm{C}$ por $3 \mathrm{~h}$. Para reidratação dos cortes as lâminas foram colocadas em etanol $100 \%$, etanol $95 \%$, etanol $70 \%$, água corrente e água destilada por 5 min cada. A fim de realizar a recuperação antigênica, as lâminas foram colocadas em tampão citrato com pH 6,0 e levadas ao forno de banho-maria por $40 \mathrm{~min}$ a uma temperatura de $95^{\circ} \mathrm{C}$. Para bloquear a peroxidase endógena as laminas foram tratadas com peróxido de hidrogênio 5\% em metanol por 20 min em câmara escura, com uma repetição. Os cortes foram circulados com caneta Dako Pen (DAKO lab. Inc., New York, NY, USA) e incubados em câmara úmida e escura por $16 \mathrm{~h}$ com o anticorpo primário anti-COX-2 (IBL, JAPAN) diluído em 1:50, em SAB (albumina bovina 1\%). A seguir, as lâminas foram encubadas com o primeiro anticorpo do kit LSAB (DAKO) em câmara úmida durante $30 \mathrm{~min}$. Estes passos foram intercalados por duas ou três lavagens das lâminas em SST por 5 min, que logo foram encubadas com a streptavidina do kit LSAB em câmara úmida por $30 \mathrm{~min}$, após terem sido novamente lavadas duas vezes em SST por $5 \mathrm{~min}$. O cromógeno tetrahidrocloreto de diaminobenzedina (DAB) foi pingado nas lâminas para colorir a reação por 5 min e após, a reação foi bloqueada em água destilada. Em seguida as lâminas foram encubadas por $30 \mathrm{seg}$ em hematoxilina de Harris e lavadas em água corrente. Por fim, foram mergulhadas em água amoniacal (20\% de hidróxido de amônia em água destilada) e lavadas em água corrente, álcool e xilol para posterior montagem.

As lâminas e os prontuários foram avaliados para confirmação do laudo original do estágio e diagnóstico realizado. As lesões adenomatosas foram divididas em tubulares e vilosas. No grupo dos carcinomas o sistema de estadiamento utilizado foi de Dukes modificado por Astler-Coller, e este acrescido covencionalmente do estágio D pra traduzir a presença de metástases a distância.

A partir do laudo anatomopatológico, os casos de adenocarcinoma foram divididos em bem diferenciados, moderadamente e pouco diferenciados; e os adenomas classificados em displasias de baixo grau e alto grau. Também avaliou-se a presença de compo- 
Rev bras Coloproct Julho/Setembro, 2007
Avaliação Imunoistoquímica da Proteína Ciclooxigenase-2 nas Neoplasias

Colorretais e sua Relação com Fatores Patológicos Prognósticos

Brambilla e Cols.
Vol. 27 $\mathbf{N}^{\mathbf{3}} 3$ nente mucinoso, estroma fibrótico, padrão microacinar e invasão infiltrativa da margem.

A reação imunoistoquímica para COX-2 apresentou imagem granular no citoplasma de coloração acastanhada produzida pelo DAB, com intensidade variável. Foram considerados positivos os casos em que houve coloração de $10 \%$ das células contadas de maneira manual em campo microscópico de 400X na área total da lâmina (Figura 1). Como controle positivo foi utilizado um caso de adenocarcinoma de reto do arquivo do serviço de patologia. Os controles negativos foram obtidos a partir de biópsias de mucosa normal presente no arquivo do laboratório de patologia. Para fins diagnóstico, as lâminas foram avaliadas por patologista com experiência em diagnóstico por imunoistoquímica.

\section{RESULTADOS}

Foram analisados 65 casos de neoplasias de cólon e reto acompanhados no período de julho de 1997 a dezembro de 2001, segundo os critérios de elegibilidade referidos anteriormente. A distribuição diagnóstica e classificação dos adenocarcinomas foi a seguinte: adenoma tubular e adenoma viloso (15 casos cada), adenocarcinoma Dukes A $(n=6)$, adenocarcinoma Dukes B $(n=10)$, adenocarcinoma Dukes C $(n=10)$, e adenocarcinoma Dukes D $(n=9)$. Vinte e sete $(41,5 \%)$ pacientes eram do gênero masculino e $38(58,5 \%)$ do gênero feminino, com idade variando entre 23 e 91 anos, mediana (DP) de 62 (15) anos. Ao separar-se os casos de adenomas e carcinomas, a média de idade do grupo dos adenomas foi de 54 anos e a dos carcinomas de 62,5 anos. As características clínico-patológicas são apresentadas na Tabela 1.

$\mathrm{O}$ diâmetro dos adenomas variou de 3 até 40 mm, com média (DP) de 7,5 (4) mm para os adenomas tubulares e de 15,7 (9) mm para os vilosos.

Nos casos de adenocarcinomas, as características patológicas observadas mostraram uma variação de diâmetro de 18 até $80 \mathrm{~mm}$ com média (DP) de $47(13,2) \mathrm{mm}$, e a presença de muco foi observada em 12 casos (34\%). O padrão infiltrativo das margens tumorais foi encontrado em 21 casos (60\%) e o padrão expansivo em 14 casos (40\%). Na avaliação do padrão microacinar, nove casos mostraram-se positivos (26\%). Já a presença de estroma fibrótico foi encontrada em apenas $4(11 \%)$ casos. A classificação histológica de adenomas e carcinomas é apresentada na Tabela 2.

Dos 65 casos avaliados a proteína COX-2 foi encontrada em 35 (54\%) casos; em dez (33\%) adenomas e em 25 (71\%) carcinomas (Tabela 3). Houve expressão progressiva e significativamente maior $(\mathrm{p}=0,002)$ nos carcinomas do que nos adenomas (Figura 2). Não houve diferença estatística entre lesões COX-2 positivas localizadas no reto 15 (43\%) e lesões localizadas no cólon 20 (57\%).
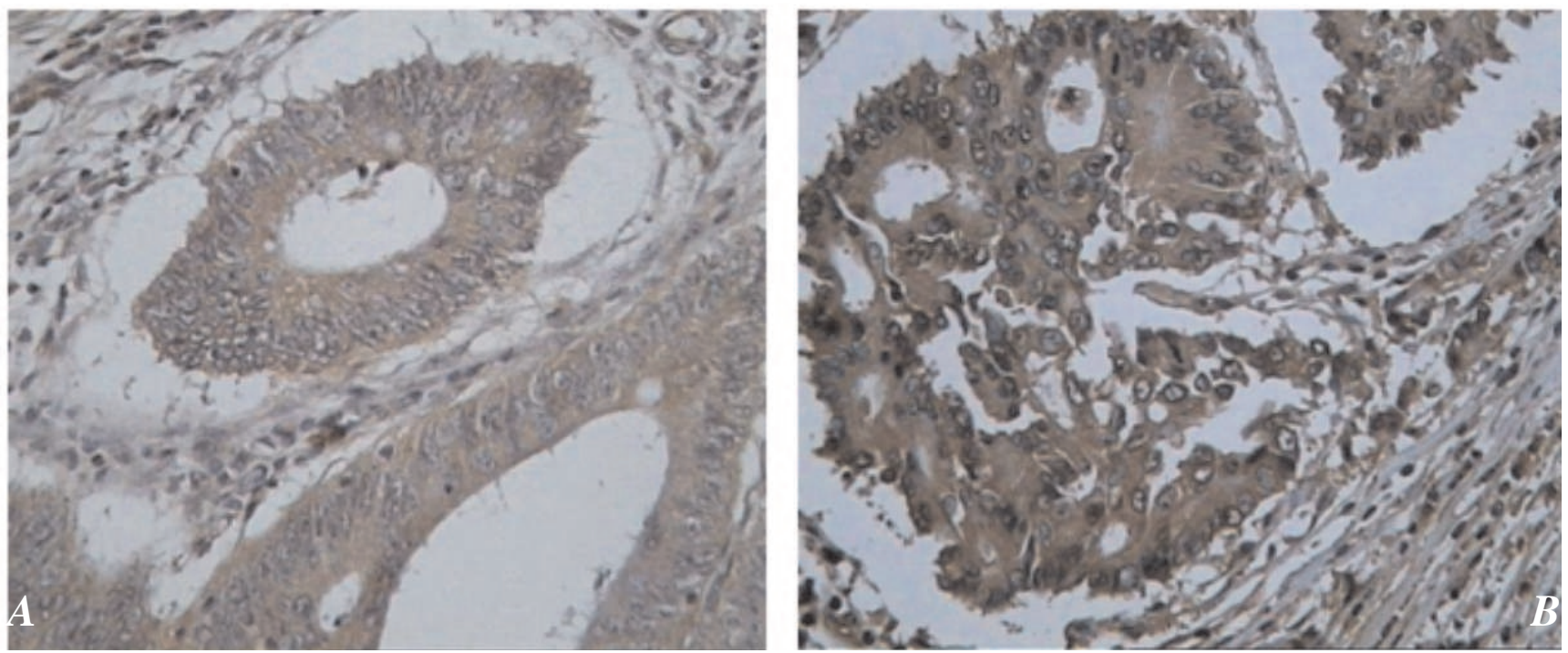

Figura 1 (A e B) - Fotomicrografia de caso representativo de adenoma tubular COX-2 positivo (IHC 400X) - Fotomicrografia de caso representativo de adenocarcinoma COX-2 positivo (IHC-40OX). 
Rev bras Coloproct Julho/Setembro, 2007
Avaliação Imunoistoquímica da Proteína Ciclooxigenase-2 nas Neoplasias Colorretais e sua Relação com Fatores Patológicos Prognósticos Brambilla e Cols.
Vol. 27 $\mathbf{N}^{\circ} 3$
Tabela 1 - Características clinicopatológicas dos casos.

\begin{tabular}{lll}
\hline Característica & $\mathbf{N}$ & $\mathbf{\%}$ \\
\hline Faixa etária (anos) & & \\
$\quad<40$ & 10 & 15 \\
$41-59$ & 21 & 32 \\
$60-79$ & 31 & 48 \\
$\quad>79$ & 03 & 05 \\
Sexo & & \\
$\quad$ masculino & 27 & 42 \\
$\quad$ feminino & 38 & 58 \\
Localização & & \\
$\quad$ reto & 24 & 37 \\
$\quad$ sigmóide & 24 & 37 \\
$\quad$ descendente & 04 & 06 \\
$\quad$ transverso & 07 & 11 \\
$\quad$ ascendente & 01 & 01 \\
$\quad$ ceco & 05 & 08 \\
Displasia & & \\
$\quad$ baixo grau & & 73 \\
$\quad$ Alto grau & 21 & 27 \\
\hline
\end{tabular}

Tabela 2 - Classificação histológica das lesões.

\begin{tabular}{lcc}
\hline Diagnóstico & Freqüência & Percentual \\
\hline Adenomas & & \\
$\quad$ Tubulares & 15 & 23 \\
$\quad$ Vilosos & 15 & 23 \\
Carcinomas & & \\
$\quad$ Dukes A & 06 & 10 \\
$\quad$ Dukes B & 10 & 15 \\
$\quad$ Dukes C & 10 & 15 \\
$\quad$ Dukes D & 09 & 14 \\
Padrão mucinoso & & \\
$\quad$ presente & 12 & 34 \\
$\quad$ ausente & 23 & 66 \\
Padrão Microacinar & & \\
$\quad$ presente & 09 & 26 \\
$\quad$ ausente & 26 & 74 \\
Padrão de Crescimento & & \\
$\quad$ infiltrativo & 21 & 60 \\
$\quad$ expansivo & 14 & 40 \\
Padrão do Estroma & & \\
$\quad$ fibrótico & 04 & 11 \\
não fibrótico & 31 & 89 \\
\hline
\end{tabular}

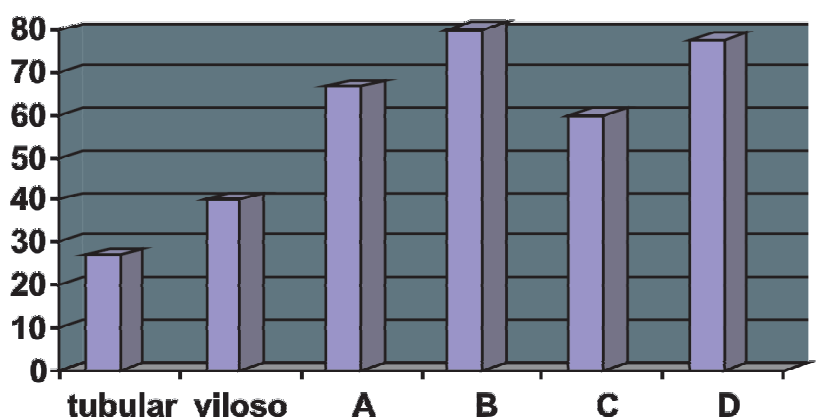

Figura 2 - Expressão da COX-2 nas neoplasias avaliadas.

Quanto ao sexo não se evidenciou diferença estatística entro sexo masculino e o sexo feminino (43\% vs $57 \%$; NS), assim como na distribuição das faixas etárias não se encontrou diferença estatística (NS).

Ao avaliar-se a relação diâmetro da lesão com a positividade para a COX-2, uma vez classificados os grupos em diâmetros até $10 \mathrm{~mm}$ e mais de $10 \mathrm{~mm}$, não se obteve diferenças entre os grupos em relação ao grau de displasia dos pólipos (32\% vs 37\%; NS).

Nos carcinomas as variáveis patológicas estudadas foram o grau de diferenciação, o caráter mucinoso da lesão, a forma de crescimento do tumor (infiltrativo ou expansivo), a presença de padrão micro-acinar e a presença de estroma fibroso, sem no entanto ter se observado diferenças significativas quanto a expressão da COX-2 em relação a estas variáveis. Estes resultados são apresentados na Tabela 4.

\section{DISCUSSÃO}

A identificação de parâmetros que reflitam o comportamento biológico do câncer correlacionando-o com a agressividade do tumor é determinante fundamental do prognóstico e do incremento da terapia oncológica. Apesar dos recentes progressos na definição dos mecanismos moleculares de desenvolvimento e progressão do câncer, somente alguns marcadores biológicos foram identificados como tendo valor prognóstico.

A literatura mostra vários estudos quanto ao valor da COX-2 como fator prognóstico das neoplasias. Ferrandina et al. demonstraram, no carcinoma de ovário, maior resistência à quimioterapia em tumores que expressavam COX $-2^{12}$. Numa revisão empreendida por Singh-Ranger e Mokbel, os autores comentam as relações da COX-2 com o câncer de mama e concluíram que existe uma clara e importante relação entre a 
Avaliação Imunoistoquímica da Proteína Ciclooxigenase-2 nas Neoplasias Colorretais e sua Relação com Fatores Patológicos Prognósticos Brambilla e Cols.

Tabela 3 - Expressão detalhada da COX-2 à imunoistoquimica.

\begin{tabular}{lcccccc}
\hline Expressão & \multicolumn{2}{c}{ Adenomas } & & \multicolumn{2}{c}{ Carcinomas } \\
da COX-2 & Tubular & Viloso & A & B & C & D \\
& $\mathbf{N}(\%)$ & $\mathbf{N}(\%)$ & N $(\%)$ & $\mathbf{N}(\%)$ & $\mathbf{N ~}(\%)$ & $\mathbf{N}(\%)$ \\
\hline Positivo & $04(27)$ & $06(40)$ & $04(66)$ & $08(80)$ & $06(60)$ & $07(78)$ \\
Negativo & $11(73)$ & $09(60)$ & $02(44)$ & $02(20)$ & $04(40)$ & $02(22)$ \\
\hline
\end{tabular}

carcinogênese mamária e a COX-2 e que os AINEs podem ter imenso valor quando usados em grupos específicos ${ }^{13}$.

Quanto ao câncer colorretal, muitos trabalhos têm dado ênfase ao valor prognóstico da COX-2. Sheehan et al. observaram uma relação do grau de expressão da COX-2 com o estadiamento de Dukes, e com a sobrevida ${ }^{14}$. Yamauchi et al. demonstram também relação da expressão da COX-2 com pior prognóstico, e maior probabilidade de metástase hepática metacrônica ${ }^{15}$. Masunaga et al., igualmente, encontraram relação da expressão da COX-2 com o estadiamento de Dukes e maior número de linfonodos comprometidos, porém, em análise multivariada, estes fatores não demonstraram associação suficiente para terem valor prognóstico independente ${ }^{16}$. Outro estudo que investigou a relação da expressão da COX-2 com o estadiamento foi o realizado por Zhang et al., não tendo os autores conseguido estabelecer relação da COX-2 com a sobrevida, mesmo sendo significante a relação de expressão da COX-2 com o estadiamento de Dukes ${ }^{17}$. No relato de Tomazawa et al., a COX-2 não se correlacionou com o estadiamento de Dukes, porém a recorrência tumoral, principalmente de metástases hematogênicas, e o intervalo livre de doença mostraram diferenças estatísticas ${ }^{18}$. Em estudo de sobrevida realizado por Hull et al. em pacientes com metástase hepáticas submetidos à cirurgia, foi encontrada a presença de COX-2 em 100\% dos casos, e o prognóstico não variou com o nível de expressão das lesões ${ }^{19}$. Em carcinomas de reto, Petersen et al. demonstraram que a expressão da COX-2 não constitui fator prognóstico na recorrência local e na sobrevida ${ }^{20}$. No presente estudo, não se estabeleceu relação entre a expressão da COX-2, a classificação de Dukes e parâmetros patológicos de mau prognóstico.

No estudo aqui apresentado, notou-se diferença significativa na expressão da COX-2 entre adenomas e carcinomas. Não se constatou, no entanto, diferença estatística entre os adenomas tubulares e vilosos, e

Tabela 4 - Características patológicas e expressão da COX-2.

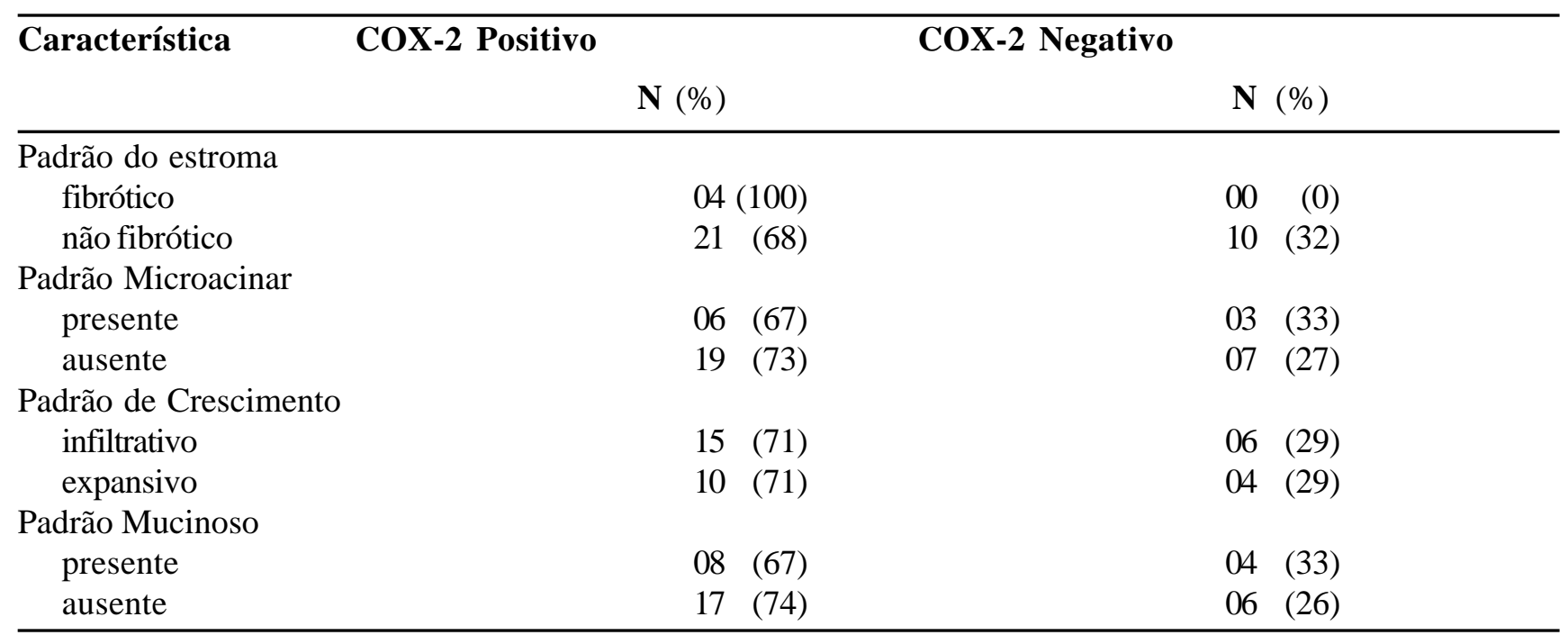


Avaliação Imunoistoquímica da Proteína Ciclooxigenase-2 nas Neoplasias

Colorretais e sua Relação com Fatores Patológicos Prognósticos

Brambilla e Cols. tampouco entre os carcinomas em diferentes estágios. Na literatura, há diversos relatos usando diferentes métodos de avaliação de expressão da COX-2 e, conseqüentemente, com resultados conflitantes.

Segundo dados da literatura, a técnica de imunoistoquímica tem sido a mais empregada, com trabalhos que adotam as mais variadas abordagens. Neste estudo com o método da imunoistoquímica obtevese positividade para COX-2 em $33 \%$ dos adenomas e $71 \%$ dos carcinomas. Usando apenas carcinomas, resultados semelhantes foram encontrados por Yamauchi et al. que também mostraram uma expressão de COX2 em $71 \%$ dos espécimes analisados ${ }^{15}$. Por outro lado, Sheehan et al. apresentaram resultados de $100 \%$ de expressão, com variação de grau de acordo com o estágio da lesão ${ }^{14}$. A mesma discordância em freqüência pode ocorrer com os adenomas. Fujita ${ }^{21}$ relatou expressão de $38 \%$ e, em outro estudo, Khan demonstrou a presença de $100 \%$ de expressão da COX $-2^{22}$. Outro fator que dificulta a avaliação são os escores de positividade, que variam amplamente entre os autores. A maioria adota escores semiquantitativos baseados no percentual de células tumorais imunorreativas, os quais muitas vezes diferem entre os autores ${ }^{14,15,22}$. Em nosso meio Jurach et al. encontraram pontos de corte apenas aos $10 \%$ quando avaliaram a positividade do p53 no prognóstico de tumores de reto ${ }^{23}$. No presente estudo, consideraram-se positivos todos os casos que exibiam $10 \%$ das células epiteliais coradas, não se utilizando graduação para os mesmos.

Paralelamente a determinação da prevalência da expressão imunoistoquímica da $\mathrm{COX}-2$, procurouse identificar alguma associação dessa expressão com características clínico-patológicas do adenocarcinoma colorretal na amostra estudada. $\mathrm{Na}$ análise univariada, não foi constatada qualquer associação entre a expressão imunoistoquímica da proteína e parâmetros clínico-patológicos. Fatores como o caráter mucinoso, presença de estroma fibrótico, padrão microacinar e crescimento de caráter infiltrativo não diferiram estatisticamente na expressão da COX-2. Mostrou-se, porém, uma tendência, sem significância estatística, de os adenomas que expressam a COX-2 possuírem maior diâmetro, dado este que possui correspondência com trabalhos como o de Hasegawa et al., que demonstraram aumento na expressão da COX-2 relacionada com o diâmetro do adenoma estudado ${ }^{24}$. Neste trabalho, não se observou diferença na expressão imunoistoquímica da COX-2 em relação ao estadiamento segundo Dukes, o que difere dos resultados apresentados por Sheehan et al. ${ }^{14}$, Yamauchi et al. ${ }^{15}$. e Hull et al. ${ }^{25}$, que verificaram aumento da expressão da proteína associado a um grau de pior prognóstico na classificação de Dukes.

Dimberg et al. ${ }^{26}$ relataram diferença significativa na expressão da COX-2 entre neoplasias localizadas em cólon e reto. Os autores atribuiem essa diferença à natureza biológica diversa entre neoplasias de cólon e reto. Esse trabalho é contestado sobretudo por Hull et al. ${ }^{27}$, que referiram diversos estudos com valores de expressão homogênea entre cólon e reto. Este estudo, concentrou-se na análise de casos de câncer colorretal esporádico e não foi encontrada diferença estatística entre as neoplasias do cólon e reto quanto à expressão da proteína COX-2.

Sinicrope et al. ${ }^{28}$ avaliaram três grupos de câncer colorretal: o esporádico, o relacionado a polipose adenomatosa familiar e o câncer colorretal hereditário não polipóide. Os resultados mostraram diferença significativa em relação à presença da expressão da COX2; nos portadores de câncer relacionado a polipose adenomatosa familiar a expressão da COX-2 foi de $100 \%$, decaindo para $92 \%$ nos casos de câncer colorretal esporádico, e para apenas $67 \%$ nos de carcinoma colorretal hereditário não polipóide. Enfatizase o fato de todos os pacientes com câncer colorretal hereditário não polipóide possuírem instabilidade de microssatélites. A hipótese aventada por Sinicrope et al. é que mutações inativadoras no gene TGF-â RII poderiam diminuir a expressão da proteína COX-2. Porém, o estudo dos casos de câncer colorretal hereditário não polipóide com mutações em hMLH1 e hMSH2 e mutações RII evidenciou não haver diferença significativa na presença ou não da expressão da proteína. Outro estudo que mostra a freqüência baixa de COX-2 nas neoplasias colorretais foi realizado por Karnes et al. ${ }^{29,30}$, segundo os quais $65 \%$ dos adenocarcinomas colorretais não expressaram COX2. Essas neoplasias apresentavam instabilidade de microssatélites e ocorriam predominantemente no cólon direito. Esses dados se contrapõem aos de Shao et al. ${ }^{31}$, que evidenciaram $100 \%$ de positividade em carcinomas de pacientes portadores de HNPCC e com mutações em hMLH1 e hMSH2. Esses mesmos autores demonstraram também seus resultados com o TGFâ1, onde o fator de crescimento foi encontrado em $100 \%$ das neoplasias com instabilidade de microssatélites além de o mesmo induzir a expressão da proteína COX-2 em cultura de células epiteliais intestinais de ratos. 
Rev bras Coloproct Julho/Setembro, 2007
Avaliação Imunoistoquímica da Proteína Ciclooxigenase-2 nas Neoplasias Colorretais e sua Relação com Fatores Patológicos Prognósticos

Brambilla e Cols.
Vol. 27 $\mathbf{N}^{\circ} 3$
Como alguns autores ${ }^{4,30}$ sugerem que as neoplasias originadas das instabilidades de microssatélites possuem menor ligação com a COX-2, é possível inferir associação com os genes envolvidos da seqüência adenoma-carcinomas. Oshima et al. ${ }^{11}$ apresentaram interessante pesquisa com ratos modificados para a gene APC, onde demonstram a ausência de COX-2 em tecidos normais e sua presença em adenomas precoces. Os autores concluíram que a expressão do gene $\mathrm{COX}-2$, aumentava o número e o tamanho dos pólipos de forma dose-dependente em ratos mutados para o gene APC, sugerindo-a como evidência genética direta de que a COX-2 exerce papel precoce na formacão do pólipo. Outro estudo que corrobora a associação do gene APC com a COX-2 foi realizado por Yang et al. ${ }^{31}$, onde os autores dosando os níveis de prostaglandinas em pólipos de pacientes diagnosticados com PAF, mostraram que estes eram significativamente mais altos que a mucosa normal adjacente às lesões, indicando assim associação entre mutação do gene APC e aumento da atividade da COX2. Em uma pequena série de casos, Dobbie et al. ${ }^{32}$ avaliaram a relação do gene APC com a expressão da
COX-2 em pacientes com PAF tratados com meloxicam. O uso dessa droga produziu aumento da expressão da COX-2 nos adenomas avaliados após 3 meses de tratamento, juntamente com diminuição de expressão do gene APC com a não alteração dos genes c-myc e ciclina D1. Hsi et al. ${ }^{33}$ realizaram estudo em linhagem de células do câncer colorretal HT-29 e introduziram o gene APC em seu tamanho original, neste experimento a apoptose foi restaurada após a transfeccão com o gene APC, demonstrando, desse modo, a relação de controle do gene APC com a COX-2.

Muitas pesquisas apontam para a importância da COX-2 na carcinogênese colorretal, embora a forma de sua participação ainda não esteja completamente compreendida. $\mathrm{O}$ estudo ora apresentado soma-se aos demais na evidência de que a COX-2 está presente em grande parte das neoplasias colorretais, e provavelmente tenha função ativa na carcinogênese. Caberá a investigacões posteriores mostrar o real valor da COX-2, não só como fator prognóstico nos carcinomas colorretais, mas também como foco para a ação de agentes quimioprofiláticos dessa neoplasia.

\begin{abstract}
Objectives: To evaluate the prevalence of cyclooxygenase-2 (COX-2) in colorectal neoplasia and to establish the relationship with pathological factors in the prognosis of colorectal cancer. Methods: 65 colorectal neoplastic lesions were investigated by immunohistochemistry for the expression of COX-2, along with the pathological factors in prognosis and staging of lesions. Results: COX-2 was positively expressed in $27 \%$ of tubular adenomas, $40 \%$ of villous adenomas, and $70 \%$ of carcinomas. A statistically significant difference was observed among COX-2 expression in adenomas and carcinomas, but such significance was not seen among the other variables studied. Conclusion: COX-2 expression seems to correlate positively with the progression of neoplasias, yet with no influence on the pathological patterns of poor prognosis.
\end{abstract}

Key words: Cyclooxygenase-2; colorectal cancer; immunohistochemistry; carcinogenesis.

\section{REFERÊNCIAS}

1. LANDIS SH, MURRAYT, BOLDEN S, WINGO PA. Cancer Statistics, 1999. CA Cancer J Clin 1999; 49: 8-31.

2. GIOVANNUCCI E, RIMM EB, STAMPFER MJ, COLDITZ GA, ASCHERIO A, WILLETT WC. Aspirin use and the risk for colorectal cancer and adenomas in male health professionals. Ann Intern Med 1994; 121: 241-6.

3. SMALLEY V, RAY WA, DAUGHERTY J, GRIFFIN MR. Use of nonsteroidal anti-inflammatory drugs and incidence of colorectal cancer: A population-based study. Arch Intern Med 1999; 159:161-6.

4. STURMER T, GLYNN RJ, LEE I, MANSON JE, BURING JE, HENNEKENS CH. Aspirin use and colorectal cancer:
Post-trial follow-up data from the physician's health study. Ann Intern Med 1998; 128: 713-20.

5. GIARDELLO FM, HAMILTON SR, KRUSH AJ, PIANTADOSI S, HYLIND LM, CELANO P, et al. Treatment of colonic and rectal adenomas with sulindac in familial adenomatous polyposis. N Engl J Med 1993; 328: 1313-6.

6. VANE JR, BOTTING RM. Mechanism of action of nonsteroidal anti-inflamatory drugs. Am J Med 1998; 104: 2s-8s.

7. SMITH WL. Prostanoid biosynthesis and mechanisms of action. Am J Physiol 1992; 263: F181-91

8. RIGAS B, GOLDMAN IS, LEVINE L. Altered eicosanoid level in human colon cancer. J Lab Clin Med 1993; 122: 51823. 
Rev bras Coloproct Julho/Setembro, 2007
Avaliação Imunoistoquímica da Proteína Ciclooxigenase-2 nas Neoplasias

Colorretais e sua Relação com Fatores Patológicos Prognósticos

Brambilla e Cols.
Vol. 27 $\mathbf{N}^{\circ} 3$
9. WINDE G, SCHIMID KW, SCHEGEL W, FISCHER R, OSSWALD H, BÜNTE H. Complete reversion and prevention of rectal adenomas in colectomized patients with familial adenomatous polyposis by rectal low-dose sulindac maintence treatment. Dis Colon Rectum 1995; 38: 813-30.

10. PASRICHA PJ, BEDI A, O 'CONNOR K, RASHID A, AKHTAR AJ, ZAHURAK ML. et al. The effects of sulindac on colorectal proliferation and apoptosis in familial polyposis. Gastroenterol 1995; 109: 995-8.

11. OSHIMA M, DINCHUK JE, KARGMAN SL, OSHIMA $\mathrm{H}, \mathrm{HANCOCK} B, \mathrm{KWONG}$, et al. Supression of intestinal polyposis in APCÄ716 knockout mice by inhibition of cyclooxygenase 2 (COX-2). Cell 1996; 87: 803-9

12. FERRANDINA G, LAURIOLA L, ZANNONI F, FAGOTTI A, FANFANI F, LEGGE F, et al. Increased cyclooxigenase-2 (cox-2) expression is associated with chemotherapy resistance and outcome in ovarian cancer patients. Ann Oncol 2002; 13: 1205-11.

13. SING-RANGER G, MOKBEL K. The role of cyclooxigenase2 (cox-2) in brest cancer, and implications of cox-2 inhibition. EJSO 2002; 28: 29-737.

14. SHEEHAN KM, SHEEHAN K, O'DONOGHUE DP, MACSWEENEY F, CONROY RM, FITZGERALD DJ, et al. The relationship between cyclooxygenase- 2 expression and colorectal cancer. JAMA 1999; 282: 1254-7.

15. YAMAUCHI $T$, WATANABE $M$, KUBOTA $T$, HASEGAWA H, ISHII Y, ENDO T, et al. Cyclooxigenase-2 expression as a new marker for patients with colorectal cancer. Dis Colon Rectum 2002; 45: 98-113.

16. MASUNAGA R, KOHNO H, DHAR DK, OHNO S, SHIBAKITA M, KINUGASA $S$, et al. Cyclooxigenase-2 expression correlates with tumor neovascularization and prognosis in human colorectal carcinoma patients. Clin Cancer Res 2000; 6: 4064-68.

17. ZHANG H, SUN XF. Overexpression of cyclooxigenase-2 correlates with advanced stages of colorectal cancer. Am J Gastroenterol 2002; 97: 1037-41.

18. TOMOZAWA S, TSUNO NH, SUNAMI E, HATANO K, KITAYAMAJ, OSADAT, et al. Cyclooxigenase-2 overexpression correlates with tumor recurrence, especially haematogenous metastasis, of colorectal cancer. British J Cancer 2000; 83: 324-8.

19. HULL MA, FENWICK SW, CHAPPLE KS, SCOTT N, TOOGOOD GJ, LODGE JP. Cyclooxigenase-2 expression in colorectal cancer liver metastases. Clinical Experimental Metastasis. 2000; 18: 21-7.

20. PETERSEN S, HAROSKE G, HELLMICH G, LUDWIG K, PETERSEN C, EICHELER W. Cox-2 expression in rectal carcinoma: Immunohistochemical pattern and clinical outcome. Anticarcer Reserch 2002; 22: 1225-30.

21. FUJITA M, FUKUI H, KUSAKA T, UEDA Y, FUJIMORI T. Immunohistochemical expression of cyclooxygenase (cox)2 in colorectal adenomas. J gastroenterol 2000; 35: 488-90.

22. KHAN KNM, MASFERRER JL, WOERNER BM, SOSLOW R, KOKI AT. Enhanced cyclooxigenase-2 expression in sporadic and familial adenomatous polyposis of the human colon. Scand J Gastroenterl 2001; 36: 865-9.

23. JURACH MT. Expressão do P53 e relação clínico-patológica no adenocarcinoma de reto: resultados preliminares. Dissertação de mestrado. Universidade Federal do Rio Grande do Sul. Programa de pós-graduação em medicida: cirurgia. 2003.

24. HASEGAWA K, ICHIKAWA W, FUJITA T. Expression of cyclooxigenase-2 (cox-2) mRNA in human colorectal adenomas. Euro J Cancer 2001; 37: 1469-74.

25. HULL MA, FENWICK SW, CHAPPLE KS, SCOTT N, TOOGOOD GJ, LODGE JP. Cyclooxigenase-2 expression in colorectal cancer liver metastases. Clinical Experimental Metastasis. 2000; 18: 21-7.

26. DIMBERG J, SAMUELSSON A, HUGANDER A, SÖDERKVIST. Differential expression of cyclooxigenase 2 in human colorectal cancer. Gut 1999; 45: 730-2.

27. HULL M, LANGMAN M. Differential expression of cyclooxygenase 2 in human colorectal cancer. Gut 2000; 47: 154-8.

28. SINICROPE FA, LEMOINE M, XI L, LYNCH PM, CLEARY KR, SHEN Y, et all. Reduced expression of cyclooxigenase 2 protein in hereditary nonpolyposis colorectal cancers relative to sporadic cancers. Gastroenterol 1999; 117: 350-8.

29. KARNES WE. Implications of low cox-2 expression in colorectal neoplasms with defective DNA mismatch repair. J Cell Biochem Suppl 2000; 34: 23-7.

30. KARNES WE, SHATTUCK-BRANDT R, BURGART LJ, DUBOIS RN, TESTER DJ, CUNNINGHAM JM, et all. Reduced cox-2 protein in colorectal cancer with defective mismatch repair. Cancer Res 1998; 58: 5473-7.

31. SHAO J, SHENG H, ARAMANDIA R, PEREIRA MA, LUBET RA, HAWK E, ET AL.. Coordinate regulation of cyclooxygenase- 2 and TGF-â1 in replication error-positive colon cancer and azoxymethane-induced rat colonic tumors. Carcinogenesis 1999; 20: 185-91.

32. YANG VW, SHIELDS JM, HAMILTON SR, SPANNHAKE EW, HUBBARD WC, HYLIND LM, et all. Size-dependent increase in prostanoid levels in adenomas of patients with familial adenomatous polyposis. Cancer Res 1998; 58: 1750-3.

33. DOBBIE Z, MULLER PY, HEINIMANN K, ALBRECHT C, D`ORAZIO D, et all. Expression of cox-2 and wnt pathway genes in adenomas of familial polyposis patients treated with meloxicam. Anticancer Res 2002; 22: 2215-20.

34. HSI LC, ANGERMAN-STEWART J, ELING TE. Introduction of full-length APC modulates cyclooxygenase-2 expression in HT-29 human colorectal carcinoma cells at the translational level. Carcinogenesis 1999; 20: 2045-9.

\section{Endereço para correspondência:}

Rua General Arcy da Rocha Nóbrega, 401/705

Madureira-Caxias do Sul/RS

95040-000

Fone/Fax: (54) 32229874

E-mail: brambilla.procto@terra.com.br 